\title{
A Rare Case of Granulomatous Hepatitis After Intravesical BCG Treatment
}

\author{
(1) Erhan Erdoğan MD, ( Erçin Altıok MD \\ University of Health Sciences, Kanuni Sultan Süleyman Training and Research Hospital, Department of Urology, Istanbul, Turkey
}

\begin{abstract}
Tumor recurrence following transurethral resection is common in non-muscle invasive urothelial cancers of the bladder. Intravesical Bacillus CalmetteGuerin (BCG) is frequently used in urology practice to prevent this recurrence and tumor progression. In this study, we present a case of Granulomatous Hepatitis that rarely develops during intravesical BCG application and that improved with anti-tuberculosis treatment.
\end{abstract}

Keywords: BCG, Hepatititis, bladder cancer

\section{Introduction}

Bacillus Calmette-Guerin (BCG), an attenuated live strain of Mycobacterium bovis, was first administered intravesically by Morales et al. (1) in 1976 for high-risk superficial bladder cancer. BCG, which is applied intravesically to prevent tumor recurrence in the treatment of superficial bladder cancer, is thought to have an anti-tumor effect by creating an immune response through T-cell in the bladder (2). Local and systemic side effects may occur after intravesical BCG administration. Although these side effects are generally mild, they can rarely be serious and lifethreatening. Cystitis, dysuria, pollakiuria and fever are the most common side effects and systemic side effects such as myalgia, headache, arthralgia, anorexia, malaise, diarrhea, chills, tremors, fatigue, high fever, arthritis, pneumonia, hepatitis, renal abscess, cytopenia and sepsis may also be seen (3).

In this article, a case of superficial bladder tumor with granulomatous hepatitis developed after intravesical BCG administration is presented.

\section{Case Report}

A 70-year-old male patient underwent transurethral resection with the diagnosis of bladder tumor. The pathology was superficial transitional cell carcinoma with no muscle invasion (pT1G2) and the patient was given intravesical BCG treatment once a week for six weeks starting four weeks after the operation (4). Three days after the sixth dose, the patient presented with severe headache, frequent urination, $39^{\circ} \mathrm{C}$ fever, chills and tremor. The laboratory tests were as follows: blood leukocyte count $=6000 / \mathrm{mm}^{3}$, erythrocyte count $=4750000 / \mathrm{mm}^{3}, \mathrm{CRP}=109$ $\mathrm{mg} / \mathrm{dL}$, Aspertate aminotransferage $(A S T)=311 \mathrm{U} / \mathrm{L}$, Alanine amino transferase $(A L T)=330 \mathrm{U} / \mathrm{L}$, total protein $=5.53 \mathrm{~g} / \mathrm{dL}$, albumin=3.8 g/dL. Hepatitis A virus, Hepatitis C virus, Human immunodeficiency virus and Brucella tube agglutination tests were negative. There was no pathological finding on chest X-ray. No growth was detected in blood and urine cultures. Abdominal ultrasonography, and cranial and abdominal tomography were unremarkable.

The patient underwent liver biopsy and histopathological examination revealed granulomatous lesions characterized by the collection of mononuclear cells, mainly macrophages, in the portal areas and surrounded by fibroblasts and lymphocytes, and granulomatous hepatitis was diagnosed (Figure 1). ARB tests in sputum and urine were negative. Granulomatous hepatitis was thought to occur due to intravesical BCG instillation and the patient was consulted to Department of Infectious Diseases. Triple anti-tuberculosis treatment (Rifampicin $600 \mathrm{mg} /$ day, INH $300 \mathrm{mg} /$ day and Ethambutol $1200 \mathrm{mg} /$ day) was started. Fever returned to normal 15 days after the initiation of treatment. All laboratory tests returned to normal six weeks later, and the patient is still being followed up by Urology and Infectious Diseases clinics.

\section{Discussion}

BCG, an attenuated live strain of $M$. bovis, was first administered intravesically by Morales et al. (1) in 1976 for high-risk superficial bladder cancer (5). Intravesical BCG administration reduces bladder tumor recurrence through anti-tumor effect. Following administration, T-lymphocyte infiltration occurs in the lamina propria layer of the bladder, which causes an increase in cytotoxic $T$ cells. The resulting local inflammation causes damage to tumor cells and anti-tumoral effect is observed $(2,6)$.

Address for Correspondence: Erhan Erdoğan MD, Department of Urology, Kanuni Sultan Süleyman Training and Research Hospital, University of Health Sciences, İstanbul, Turkey Phone: +90 0212441500 E-mail: erhandr@hotmail.com ORCID: orcid.org/0000-0003-0910-5370 


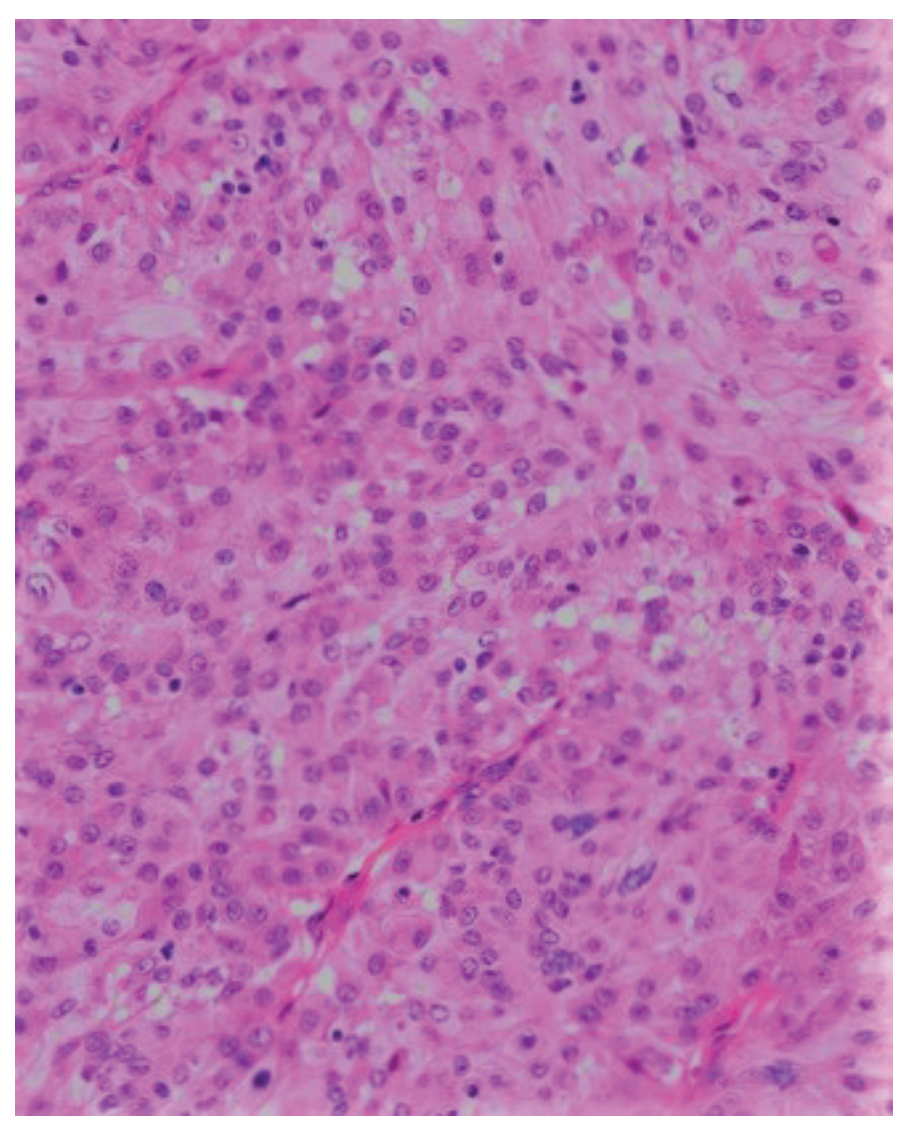

Figure 1. Granulomatous structures consisting of polymorphonuclear leukocytes in portal areas was observed. (Stained with hemotoxylin-eosine, H\&Ex40)

Local and systemic side effects may occur after intravesical BCG administration. Although these side effects are generally mild, they can rarely be serious and life-threatening (7). The most common local side effects after application are cystitis, dysuria, pollakiuria and fever, while systemic side effects such as myalgia, headache, arthralgia, anorexia, malaise, diarrhea, chills, weakness, high fever, arthritis, pneumonia, hepatitis, renal abscess, cytopenia and sepsis may also occur. Systemic side effects are less common than local side effects. In a study by Steg et al. (2), the rate of systemic side effects was reported as 3\%. There are those who argue that systemic complications are due to immunoallergic reaction after intravesical BCG application, as well as there are authors suggesting hematogenous spread of bacteria due to damaged urothelium secondary to traumatic catheterization, bladder perforation and excessive tumor resection $(8,9)$.

Intravesical BCG should be discontinued in patients with systemic side effects. In particular, patients with high fever should be followed closely, and patients with fever above $39^{\circ} \mathrm{C}$ should be hospitalized (10). In a study by Paterson et al. (10), patients with fever above $39^{\circ} \mathrm{C}$ within 48 hours following intravesical BCG treatment were hospitalized. Patients with no bacterial growth in blood and urine cultures despite ongoing fever were given $300 \mathrm{mg}$ isoniazid treatment, and a rapid response was observed and fever decreased.
Impaired liver function tests and high fever during intravesical BCG therapy should be considered for granulomatous hepatitis. Anti-tuberculosis treatment should be started at the first stage in cases with confirmed granulomatous hepatitis. Steroid should be added to the treatment in patients whose liver function tests do not improve despite six months of treatment (2). In our case, cure was achieved with anti-tuberculosis treatment without the need for steroid treatment.

In order to prevent complications after intravesical BCG administration, Lamm et al. (8). reported that prophylactic isoniazid administration, which was started on the morning of treatment and used for three days, could prevent severe irritative symptoms and systemic complications.

\section{Conclusion}

Local and systemic side effects of intravesical BCG can be seen in the treatment of superficial bladder cancer and carcinoma in situ. Although local side effects are more frequent, they are better tolerated by patients. Although systemic side effects are rare, such patients should be closely monitored, and liver biopsy should be initiated for definitive diagnosis, especially in patients with impaired liver function.

\section{Ethics}

Informed Consent: Informed consent was obtained from all the patients.

Peer-review: Externally peer-reviewed.

\section{Authorship Contributions}

Concept: E.E., Design: E.A., Data Collection or Processing: E.A., Analysis or Interpretation: E.A., Literature Search: E.A., Writing: E.E.

Conflict of Interest: No conflict of interest was declared by the authors.

Financial Disclosure: The authors declared that this study received no financial support.

\section{References}

1. Morales A, Eidinger D, Bruce AW. Intracavitary Bacillus CalmetteGuerin in the treatment of superficial bladder tumors. J Urol 1976;116:180-183.

2. Steg A, Leleu C, Debre B, et al. Systemic bacillus CalmetteGuerin infection, 'BCGitis', in patients treated by intravesical bacillus Calmette-Guerin therapy for bladder cancer. Eur Urol 1989;16:161-164.

3. Soylu A, Ince AT, Polat $H$, et al. Peritoneal tuberculosis and granulomatous hepatitis secondary to treatment of bladder cancer with Bacillus Calmette-Guerin. Ann Clin Microbiol Antimicrob. 2009;8:12.

4. Brausi M, Oddens J, Sylvester R, et al. Side effects of Bacillus Calmette-Guerin (BCG) in the treatment of intermediate-and highrisk Ta, $\mathrm{T} 1$ papillary carcinoma of the bladder: results of the EORTC genito-urinary cancers group randomised phase 3 study comparing one-third döşe with full döşe and 1 year with 3 years of maintenance BCG. Eur Urol 2014;65:69-76.

5. Yücetaş U, Toktaş G. BCG komplikasyonları ve başa çıkma. Bull Urooncol 2011;1:23-25. 
6. Prescott $\mathrm{S}$, James K, Hargreave TB, et al. Intravesical Evans strain BCG therapy: quantitative immunohistochemical analysis of the immune response within the bladder wall. J Urol 1992;147:1636-1642.

7. Rischmann P, Desgrandchamps F, Malavaud B, Chopin DK. BCG intravesical instillations: recommendations for side-effects management. Eur Urol. 2000;37:33-36.

8. Lamm DL, van der Meijden PM, Morales A, et al. Incidence and treatment of complications of Bacillus Calmette-Guerin intravesical therapy in superficial bladder cancer. J Urol 1992;147:596-600.
9. Leebeek FW, Ouwendijk RJ, Kolk AH, et al. Granulomatous hepatitis caused by bacillus Calmette-Guerin (BCG) infection after BCG bladder instillation. Gut 1996;38:616-618.

10. Paterson DL, Patel A. Bacillus Calmette Guerin (BCG) immunotherapy for bladder cancer: Review of complications and their treatment. Aust N Z J Surg 1998;68:340-344. 